\title{
The Effects of Organizational Cohesiveness on Organizational Performance: A Study on the Egyptian Commercial Banks
}

\author{
Wageeh Nafei ${ }^{1}$ \\ ${ }^{1}$ University of Sadat City, Menoufia, Egypt \\ Correspondence: Wageeh Nafei, University of Sadat City, Menoufia, Egypt. E-mail: dr.wageeh1965@yahoo.com
}

Received: March 3, 2014

Accepted: November 20, 2014

Online Published: February 25, 2015

doi:10.5539/ibr.v8n3p54

URL: http://dx.doi.org/10.5539/ibr.v8n3p54

\begin{abstract}
Organizational Cohesiveness (OC), and Organizational Performance (OP) have become the organizational behavior and human resources management hot spots. OC refers to two main constructs, namely, task cohesion and social cohesion. The purpose of this study is to investigate the relationships between OC (IATG-T, IATG-S, GI-T and GI-S) and OP at the Egyptian commercial banks.

Using Carron, et al. (1985) of OC, the study develops a number of hypotheses and tests them. This research is an applied form in terms of its goals and is descriptive in terms of the method of data collection. Of the 382 questionnaires distributed, 315 usable questionnaires were returned, a response rate of $82 \%$.

The results showed that OC significantly is related to the OP. In other words, both task cohesion and social cohesion significantly correlated with OP. The results also showed that the degree of OC among members determines the success of cooperative OP in moving toward its future direction.

The study suggests that the Egyptian commercial banks can improve OP by influencing its OC, specifically, by developing IATG-T, IATG-S, GI-T and GI-S. The study provided that it is necessity to pay more attention to the dimensions of OC as a key source for organizations to enhance the competitive advantage which is a prime significance for OP.

The study observes that there is a critical shortage of $\mathrm{OC}$ and that a greater understanding of the factors that influence the OP, including IATG-T, IATG-S, GI-T and GI-S, is of great importance. Therefore, this study is to examine the relationship between OC and OP among employees at the Egyptian commercial banks.
\end{abstract}

Keywords: organizational cohesiveness, organizational performance

\section{Introduction}

Organizational Cohesiveness (OC), and Organizational Performance (OP) have become the organizational behavior and human resources management hot spots. In the process of the organizational operation, there are cohesiveness and psychological contract which are informal and implied in the heart of employee except for the formal economic contract kept by written. Though they have not strong sanctions as the economic and legal contract, they are also dominant factors in determining the attitude and obligation of employees towards organization.

OC can be defined as the tendency for a group to stick together and remain united in the pursuit of their instrumental objectives and/or for the satisfaction of member affective needs, as a multidimensional construct comprised of both task and social aspects, and involving the dual processes of integration into the group and attraction toward other group members. Thus, four dimensions come into sight: Individual Attractions to the Group-Social (IATG-S), Individual Attractions to the Group-Task (IATG-T), Group Integration-Social (GI-S) and Group Integration-Task (GI-T) (Carron et al., 1982; 1985; 1998).

The perception of high levels of OC is highly related to the sensation of the group unit, the collective and interdependence with the team members, while the perception of low levels of OC is related to the sensation of individual orientation, the nonexistence of cooperation and independence of the team members (Carron et al., 1998). The OC will decide the successfulness of cooperatives' activities such as in the economic, social and cultural aspects. OC is indispensable in the study of group dynamics (Sapran, 2010).

The purpose of this study is to investigate the relationship between OC (task cohesion and social cohesion) and OP 
at the Egyptian commercial banks. The study is structured as follows: Section one is introductory. Section two gives a theoretical construct of OC and OP. Section three presents the research model. Section four presents the research questions and hypotheses. Section five deals with the research methodology. Section six presents the hypotheses testing. Section seven explains the research findings. Section eight deals with the discussion. Finally, section nine presents the main conclusion of the study.

\section{Literature Review}

\subsection{Organizational Cohesiveness}

Researchers have defined OC in a variety of ways. OC, originated from "Cohaesus", a Latin word, means binding intimately and closely and is a dynamic process (Chidambaram \& Jones, 1996).

OC refers to the dynamic process in which team members work closely to accomplish objectives and goals of their team (Chelladurai \& Carron, 1982). OC should be examined in relation to both the task- and social-oriented concerns of the group. Cognitions about the cohesiveness of the group are related to the group as a totality and to the manner in which the group satisfies personal needs and objectives (Carron et al., 1985). OC reflects team spirit and desire to stay within a group (Robbins, 1993). Higher OC means more belonging (Carron \& Brawley, 1985). $\mathrm{OC}$, which is a dynamic process, is the power behind group interactions. Team members with a high level of OC have more common interests and ends (Keller, 1986).

OC members have more desire to group and cooperate (Mullen \& Cooper, 1994). Lower OC means employees may leave their organization (O'Reilly et al., 1991). OC decides members' wanting to stick to their team and the level of commitment. (Corey, 1992).

It is the commitment of members to the group task. It is the resistance of a group to disruptive forces (Cota et al., 1995). OC is the emotional and mental power urging employees towards more binding (Clark et al., 2009).

OC could be categorized into two major groups: (a) group integration (GI: "a member's perceptions of the group as a totality"); and (b) individual attraction to group (ATG: "a member's personal attraction to the group"). Furthermore, GI and ATG could be focused on either the task or the social aspect of the group. Consequently, OC comprises four separate but related dimensions (Carron et al., 1985; 2002):

1) Individual Attractions to the Group-Task (i.e., the individual group member's perceptions of his/her personal involvement in task aspects of the group; IATG-T).

2) Individual Attractions to the Group-Social (i.e., the individual group member's perceptions of his/her involvement in social aspects of the group; IATG-S).

3) Group Integration-Task (i.e., the individual group member's perceptions of the degree of unity the group possesses surrounding task aspects; GI-T).

4) Group Integration-Social (i.e., the individual group member's perceptions of the degree of unity the group possesses regarding social aspects; GI-S).

The work of Carron et al. (1985) offered a promising future to OC research because (a) the task-social and individual-group dimensions are important to understanding OC in many types of groups and have been identified independently by other researchers; and (b) the implications of the two-dimension model have been tested with the Group Environment Questionnaire (GEQ) in a growing number of empirical reports (Cota et al., 1995).

Carron et al. $(1985 ; 1998)$ developed an operationalization of OC called the GEQ which contains 18 items that assess the four dimensions of OC. Overall, the utility of the GEQ has been supported through a number of studies. GEQ subscale scores had separate and meaningful patterns of correlations with variables that were important to group functioning and effectiveness (Boone et al., 1997; Gardner et al., 1996; Li \& Harmer, 1996; Prapavessis \& Carron, 1997; Shields et al., 1997). The GEQ is a useful and contemporary measurement approach to OC. However, on a few occasions, researchers have questioned the validity of the GEQ based on independent analyses of the factor structure of the instrument (Dion, 2000; Sullivan et al., 2002). The GEQ, which was revised to measure OC is indispensable. This questionnaire has 18 questions and adopts the Likert five-point scale. All points were summed up and then averaged. A higher score refers to higher OC (Carron et al., 1985).

\subsection{Organizational Performance}

OP is a determinant of its very existence. Systematic or abrupt decline in OP level may lead to organizational death or mortality (Baum \& Singh, 1994), a situation that occurs when an organization fails, closes down its operations, and disbands its constituent elements (Carroll \& Delacroix, 1982).

Despite the large corpus of research and studies on OP, no agreement on the concept of OP is found. In spite of this 
difference, most researchers express their OP through the success achieved by the organization in achieving its objectives. OP is a reflection of the organization's ability to achieve its goals, or in other words, the organization's ability to achieve long-term goals (Miller \& Broamiley, 1990).

OP can be defined as a combination of resources, capabilities of the organization that are being used efficiently and effectively in order to achieve its objectives (Collis \& Montgomrey, 1995). It is the level of the outputs of the organization after conducting operations on its inputs. OP is the output of the activities that occur within the organization (Wit \& Meyer, 1998).

Hence, after a thorough review of the different concepts of OP, it can be argued that OP in its simplest form is the desired results which the organization seeks to achieve efficiently and effectively. Darroch (2003) maintains that the dimensions of OP are in two basic dimensions of OP. They can be explained as follows:

1) Comparative Performance refers to the understanding of the different categories of employees to the level of profitability of the organization where they work, the market share, and the level and speed of growth of the organization compared to organizations working in the same area.

2) Internal Performance refers to the understanding of the different categories of employees to the level of the $\mathrm{OP}$ to which they belong in the short term and long-term, and also the possibility of achieving the OP targets set for the organization, both in the short term and long term.

\subsection{The Relationship between $O C$ and $O P$}

OC is investigated to decide its development and impact on OP (Stogdill, 1972). The relationship between OC and OP had been studied extensively. Earlier researchers were unable to find a systematic relationship between OC and OP (Mitchell, 1982). More OC are more effective in achieving OP (Shaw, 1981; Dorfman \& Stephan, 1984). A higher OC (task cohesion) raises possibility of attaining higher profit than a higher OC (social cohesion) (Hunger \& Wheelan, 1984)

$\mathrm{OC}$ and $\mathrm{OP}$ are examined from the perspective of the employees. This makes it interesting whether there is specific research concerning the team member's perspective of OP. OC accounted for unique variance while using member ratings of OP (Keller, 1986).

The high OC would lead to more team success, more collective efficacy and better group communication (Bettenhausen, 1991). The positive relationship between OC and OP can be found in the meta-analysis. These relationships as "moderately strong and positive" (Evans \& Dion, 1991). A questionnaire assessing OC and OP and administered to members of nine large-scale cadet squadrons showed equally strong associations between them (Zaccaro, 1991). There are two recent meta analytic studies which concluded that a small but positive relationship between OC and OP existed (Mullen \& Copper, 1994). However, subsequent studies disagreed with these meta-analyses on whether or not the cohesion-performance relationship was moderated by other variables, such as level of analysis, task interdependency, goal acceptance, and group norm (Gully et al., 1995; Podsakoff et al., 1997).

OC was the only variable that significantly correlated with the OP and strongly predicted it (Keller, 1992). OC and OP have a deep impact. However, their integration is not conclusive (Mullen \& Copper, 1994). OC contributes to satisfaction of the group members (Zaccaro \& Lowe, 1988), and therefore has a positive impact on the OP (Langfred, 1998). OC would be important for improving OP, but more research is needed (Craig \& Kelly, 1999). OC, as a vital variable relating to OP, is worthy more investigation (Elenkov, 2002).

The link between OC and OP is that for teams with a high OC level, the productivity tended to be higher as group members defended the group norms and felt a sense of security because of the group. Why do we investigate the relationship between OC and OP if the evidence of a positive relationship is overwhelming? There is still more empirical research necessary to discover "if the OC factor alone leads to a better team OP". The expected positive relationship doesn't mean that there is no question about the relationship between OC and OP. If you take a critical look at the OC literature you might say that too much of focus has been on individuals as opposed to the group as a whole, resulting is losing the clear view on OC (Dyaram \& Kamalanabhan, 2005).

The norm of OC influenced the cohesion-performance relationship and supported the theoretical proposition that higher OC related to better OP (Patterson et al., 2005). OC had a stronger relationship with OP, but task cohesion is higher than social cohesion. The causal relationship between OC and OP are more powerful in explaining the correlation between OC and OP (Harun \& Mahmood, 2012).

The relationship of OC to OP is complex. The evidence is convincing that success leads to higher OC, but less convincing whether OC leads to subsequent improved OP. Clearly, we need more research to fully investigate the 
relationship between OC and OP. In the learning experience, you will investigate (a) the degree of OC of successful and unsuccessful teams to determine whether success affects the amount of OC perceived by team members and (b) relationship between the two (Rachhpal et al., 2012).

\section{Research Model}

The proposed comprehensive conceptual model is presented in Figure 1. The diagram below shows that there is one independent variable of organizational cohesiveness. There is one dependent variable of OP. It shows the rational link among the two types of variables. From the above discussion, the research model is as shown in Figure 1 below.

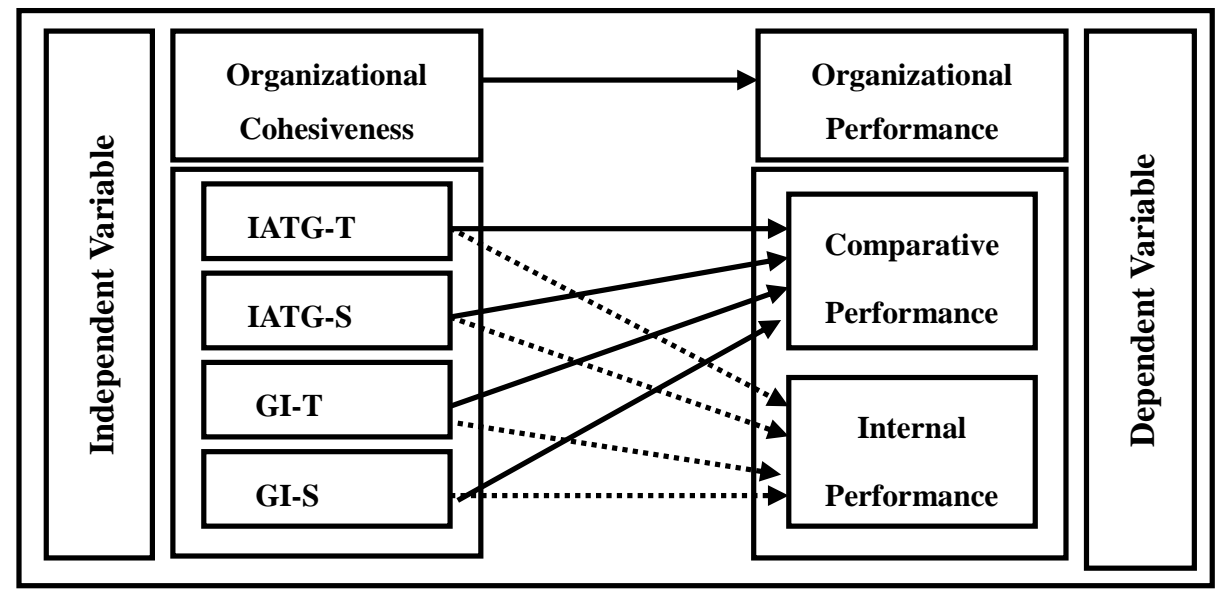

Figure 1. Proposed comprehensive conceptual model

The research framework suggests that organizational cohesiveness in an organization has an impact on OP. OC as measured consists of IATG-T, IATG-S, GI-T and GI-S (Carron et al., 1985). OP is measured in terms of comparative performance and internal performance (Darroch, 2003; Pathirage et al., 2007; Chen \& Mohamed, 2007; Lurdvall \& Nielsen, 2007).

\section{Research Questions and Hypotheses}

The research process includes both questions and hypotheses. The research questions of this study are as follows:

Q1: What is the nature and the extent of the relationship between OC (IATG-T) and OP at the Egyptian commercial banks.

Q2: What is the nature of the relationship between $O C$ (IATG-S) and OP at the Egyptian commercial banks.

Q3: What is the extent of the relationship between $O C(G I-T)$ and OP at the Egyptian commercial banks.

Q4: What is the statistically relationship between $O C(G I-S)$ and OP at the Egyptian commercial banks.

The following hypotheses were developed to the test if there is a significant correlation between OC and OP.

H1: OC (IATG-T) has no significant effect on OP at the Egyptian commercial banks.

H2: OC (IATG-S) has no significant impact on OP at the Egyptian commercial banks.

H3: OC (GI-T) has no significant effect on OP at the Egyptian commercial banks.

H4: OC (GI-T) has no significant influence on OP at the Egyptian commercial banks.

\section{Research Methods}

\subsection{Population and Sample}

The study subjects are employees at the commercial banks in Egypt, including, general commercial banks, joint commercial banks and foreign branches of banks. The total population is 66536 employees. Determination of respondent sample size was calculated using the formula (Daniel, 1999) as follows:

$$
\mathrm{n}=\frac{N \times(Z)^{2} \times P(1-P)}{d^{2}(N-1)+(Z)^{2} \times P(1-P)}
$$

The number of samples obtained by 382 employees at the Egyptian commercial banks is presented in Table 1 . 
Table 1. Distribution of the sample size

\begin{tabular}{cccc}
\hline Bank Type & Number of Population & Percentage & Sample Size \\
\hline General Commercial Banks & 52564 & $79 \%$ & $382 \times 79 \%=302$ \\
Joint Commercial Banks & 11977 & $18 \%$ & $382 \times 18 \%=69$ \\
Foreign Branches of Banks & 1995 & $3 \%$ & $382 \times 3 \%=11$ \\
Total & $\mathbf{6 6 5 3 6}$ & $\mathbf{1 0 0 \%}$ & $\mathbf{3 8 2} \times \mathbf{1 0 0 \%}=\mathbf{3 8 2}$ \\
\hline
\end{tabular}

Source: Egyptian Central Bank, Economic Magazine, 2012.

Table 2. Sample distribution

\begin{tabular}{|c|c|c|c|}
\hline Variables & Classification & Number & Percentage \\
\hline \multirow{9}{*}{ 1- Job Title } & General Manager & 18 & $5.1 \%$ \\
\hline & Deputy General Manager & 25 & $7.9 \%$ \\
\hline & Agent General Manager & 20 & $6.3 \%$ \\
\hline & Deputy Manager & 34 & $10.8 \%$ \\
\hline & Controller & 35 & $11.1 \%$ \\
\hline & Excellent Banker & 49 & $15.6 \%$ \\
\hline & Banker A & 42 & $13.3 \%$ \\
\hline & Banker B & 92 & $29.2 \%$ \\
\hline & Total & 315 & $100 \%$ \\
\hline \multirow{3}{*}{ 2- Marital Status } & Married & 215 & $68.3 \%$ \\
\hline & Single & 100 & $31.7 \%$ \\
\hline & Total & 315 & $100 \%$ \\
\hline \multirow{4}{*}{ 3- Age } & Less than 30 years & 125 & $39.7 \%$ \\
\hline & From 30 to 45 & 140 & $44.4 \%$ \\
\hline & More than 45 & 50 & $15.9 \%$ \\
\hline & Total & 315 & $100 \%$ \\
\hline \multirow{3}{*}{ 4- Educational Level } & Secondary School & 138 & $43.8 \%$ \\
\hline & University Education & 177 & $56.2 \%$ \\
\hline & Total & 315 & $100 \%$ \\
\hline \multirow{4}{*}{ 5- Period of Experience } & Less than 5 years & 65 & $20.6 \%$ \\
\hline & From 5 to 10 & 210 & $66.7 \%$ \\
\hline & More than 10 & 40 & $12.7 \%$ \\
\hline & Total & 315 & $100 \%$ \\
\hline
\end{tabular}

\subsection{Method of Data Collection}

The goal of this study was to examine the relationships between OC and OP at the Egyptian commercial banks. A survey research method was used to collect data in this study.

The questionnaire included three questions, relating to $\mathrm{OC}$, OP, and biographical information of employees at the Egyptian commercial banks.

The random sampling approach in the trial test is used. Banks were first randomly selected and contacted by phone to seek their assistance for sending questionnaires. Descriptions of testing methods as well as all relevant testing details were provided to the banks contacted.

The study subjects are full-time employees at the Egyptian commercial banks. A total of 382 questionnaires were 
sent out in December, 2013 and collected in February 2014.

Three hundred and twenty five effective questionnaires were collected (85\% collection rate). Ten ineffective ones (with unanswered questions, duplicated entries and inappropriate marks) were excluded, and the number of effective ones was 315 ( $82 \%$ valid collection rate.)

\subsection{Research Variables and Methods of Measuring}

This research studied the significant role of OC in improving OP. In referencing exiting literature, the study established a basic research model.

Figure 1 shows that organizational cohesiveness is independent variable; and OP is the dependent variable. The study of data collected through questionnaires with three: organizational cohesiveness, OP, and basic respondent demographic data.

The 18-item scale OC is based on Carron et al. (1985). The Group Environment Questionnaire (GEQ) is theoretically based on Carron's (1982) conceptual model of cohesion. This model divides cohesion into two categories; IATG and GI. These two categories are divided into four sub-scales IATG-T, IATG-S, GI-T, and GI$\mathrm{S}$. These four sub-scales describe the individual member's feeling about the their place within the team.

Carron et al. (1985) defined the four scales in the following way:

1) IATG-T: Individual team member's feeling about his or her personal involvement within the group task, productivity, and goals and objectives.

2) IATG-S: Individual team member's feeling about his or her personal acceptance, and social interaction with the group.

3) GI-T: Individual team member's feeling about the similarity, closeness, and bonding within the team as a whole around the group's task.

4) GI-S: Individual team member's feeling about the similarity, closeness, and bonding within the team as a whole around the group as a social unit.

There were four items measuring IATG-T, five items measuring IATG-S, five items measuring GI-T, and four items measuring GI-S.

The seven item scale OP is based on Darroch (2003); Pathirage et al. (2007); Chen \& Mohamed (2007); and Lurdvall \& Nielsen (2007). There were three items measuring comparative performance, and four items measuring internal performance.

Responses to all items scales were anchored on a five (5) point Likert scale for each statement which ranges from (5) "full agreement," (4) for "agree," (3) for "neutral," (2) for "disagree," and (1) for "full disagreement."

\subsection{Methods of Data Analysis and Testing Hypotheses}

The researcher has employed the following methods: (1) The Alpha Correlation Coefficient (ACC), (2) Multiple Regression Analysis (MRA), and (3) the statistical testing of hypotheses which includes F- test and T-test. They are found in SPSS.

\section{Hypotheses Testing}

Before testing the hypotheses and research questions, descriptive statistics were performed to find out means and standard deviations of OC and OP.

Table 3 lists the mean and standard deviation among variables. The mean of each variable is more than 3 , and this result indicates that the study subjects in general have a higher level of OC and OP. The different facets of OC (IATG-T, IATG-S, GI-T, and GI-S) are examined. Most respondents identified the presence of IATG-T $(\mathrm{M}=3.90, \mathrm{SD}=0.778)$. This was followed by GI-T $(\mathrm{M}=3.90, \mathrm{SD}=0.707)$, GI-S $(\mathrm{M}=3.89, \mathrm{SD}=0.776)$, and IATG-S $(\mathrm{M}=3.54, \mathrm{SD}=0.718)$. The different facets of $\mathrm{OP}$ (comparative performance and internal performance) are examined. Most respondents identified the presence of internal performance $(\mathrm{M}=3.49, \mathrm{SD}=0.710)$. This was followed by comparative performance $(\mathrm{M}=3.36, \mathrm{SD}=0.717)$. 
Table 3. The mean and standard deviations of OC and OP

\begin{tabular}{|c|c|c|c|}
\hline Variables & The Dimension & Mean & Standard Deviation \\
\hline \multirow{5}{*}{ OC } & Interpersonal Attraction to the Group-Task (IATG-T) & 3.903 & 0.778 \\
\hline & Interpersonal Attraction to the Group-Social (IATG-S) & 3.541 & 0.718 \\
\hline & Group Integration-Task (GI-T) & 3.903 & 0.707 \\
\hline & Group Integration-Social (GI-S) & 3.890 & 0.776 \\
\hline & Total Measurement & 3.800 & 0.680 \\
\hline \multirow{3}{*}{$\mathbf{O P}$} & Comparative Performance & 3.366 & 0.717 \\
\hline & Internal Performance & 3.497 & 0.710 \\
\hline & Total Measurement & 3.441 & 0.685 \\
\hline
\end{tabular}

\subsection{Evaluating Reliability}

ACC was used to evaluate the degree of internal consistency among the contents of the scale under testing. It was decided to exclude variables that had a correlation coefficient of less than 0.30 when the acceptable limits of ACC range from 0.60 to 0.80 , in accordance with levels of reliability analysis in social sciences (Nunnally \& Bernstein, 1994). Table 4 shows the results of the reliability test for each variable of OC and OP.

Table 4. Reliability of OC and OP

\begin{tabular}{clrc}
\hline Variables & The Dimension & Number of Statement & ACC \\
\hline \multirow{2}{*}{ OC } & Interpersonal Attraction to the Group-Task (IATG-T) & 4 & 0.8356 \\
& Interpersonal Attraction to the Group-Social (IATG-S) & 5 & 0.6700 \\
& Group Integration-Task (GI-T) & 5 & 0.7738 \\
& Group Integration-Social (GI-S) & 4 & 0.8313 \\
& Total Measurement & $\mathbf{1 8}$ & $\mathbf{0 . 9 3 1 8}$ \\
\hline \multirow{2}{*}{ OP } & Comparative Performance & 3 & 0.8966 \\
& Internal Performance & 4 & 0.8872 \\
& Total Measurement & $\mathbf{7}$ & $\mathbf{0 . 9 3 5 3}$ \\
\hline
\end{tabular}

To assess the reliability of the data, Cronbach's alpha test was conducted. Table 4 shows the reliability results for OC and OP. All items had alphas above 0.60 and were therefore excellent, according to Langdridge's (2004) criteria.

The 18 items of OC are reliable because the ACC is 0.9318 . The 4 items of IATG-T scales are reliable due to the fact that the ACC is 0.8356 . The IATG-S, which consists of 5 items, is reliable since the ACC is 0.6700 . The 5 items related to GI-T are reliable as ACC is 0.7738 . Furthermore, the GI-S, which consists of 4 items, is reliable due to the fact that the ACC is 0.8313 .

The 7 items of OP are reliable due to the fact that the ACC is 0.9353 . The comparative performance, which consists of 3 items, is reliable since the ACC is 0.8966 while the four items related to internal performance is reliable as the ACC is 0.8872 . Thus, the reliability of OP can be acceptable.

Accordingly, two scales were defined, OC (18 variables), where ACC represented about 0.9318 , and OP (7 variables), where ACC represented 0.9353 .

\subsection{The Relationship between $O C$ (IATG-T) and OP}

According to Table 5, the regression-coefficient between OC (IATG-T) and OP is R= 0.695 and $\mathrm{R} 2=0.483$. This means that the OP can be explained by the dimensions of OC, for example, "I'm happy that I spend time with the team at the bank" $(\beta=0.352, R=0.575$, and $R 2=0.330)$, "I'm happy I have a serious level of teamwork at the bank" ( $\beta=0.326, \mathrm{R}=0.589$, and $\mathrm{R} 2=0.346$ ), "the Bank's team gives me the opportunity to improve my performance" $(\beta=0.136, R=0.558$, and $\mathrm{R} 2=0.311)$, and "I love the style of working with members of the bank team" $(\beta=0.027, R=0.484$, and $R 2=0.234)$. 
Because of the calculated F (72.34) more than indexed F (3.31) at the statistical significance level of 0.01 , the null hypothesis is rejected.

Table 5. MRA results for OC (IATG-T) and OP

\begin{tabular}{lccc}
\hline The Variables of OC (Interpersonal Attraction to the Group-Task) & Beta & $\mathrm{R}$ & $\mathrm{R}^{2}$ \\
\hline 1. I'm happy that I spend time with the team at the bank. & $0.352^{* *}$ & 0.575 & 0.330 \\
2. I'm happy I have a serious level of teamwork at the bank. & $0.326^{* *}$ & 0.589 & 0.346 \\
3. The Bank's team gives me the opportunity to improve my performance. & $0.136^{* *}$ & 0.558 & 0.311 \\
4. I love the style of working with members of the bank team. & 0.027 & 0.484 & 0.234 \\
- Multiple Correlation Coefficients (MCC) & 0.695 \\
- Determination of Coefficient (DF) & 0.483 \\
- The Value of Calculated F & 72.341 \\
- Degree of Freedom & 4,310 \\
- The Value of Indexed F & 3.31 \\
- Level of Significance & \\
\hline
\end{tabular}

Note. $* \mathrm{P}<.05 ; * * \mathrm{P}<.01$.

\subsection{The Relationship between $O C(I A T G-S)$ and $O P$}

Table 6. MRA results for OC (IATG-S) and OP

\begin{tabular}{lccc}
\hline The Variables of OC (Interpersonal Attraction to the Group-Social) & Beta & $\mathrm{R}$ & $\mathrm{R}^{2}$ \\
\hline 1. I enjoy social activities. I have a teamwork at the bank. & $0.134^{* *}$ & 0.354 & 0.125 \\
2. I feel missing the team work at the bank when work with them is terminated. & $0.215^{* *}$ & 0.269 & 0.072 \\
3. My best friends are from within the teamwork at the bank. & $0.186^{* *}$ & 0.224 & 0.050 \\
4. I enjoy working with the team members at the bank. & $0.318^{* *}$ & 0.480 & 0.230 \\
5. The team of the bank is a significant social group to which I belong. & $0.365^{* *}$ & 0.451 & 0.203 \\
- Multiple Correlation Coefficients (MCC) & 0.617 \\
- Determination of Coefficient (DF) & 0.381 \\
- The Value of Calculated F & 38.038 \\
- Degree of Freedom & 5,309 \\
- The Value of Indexed F & 3.01 \\
- Level of Significance & & 0.01 \\
\hline
\end{tabular}

Note. $* \mathrm{P}<.05 ; * * \mathrm{P}<.01$.

According to Table 6, the regression-coefficient between OC (IATG-T) and OP is R=0.695 and R2=0.483. This means that the OP can be explained by the dimensions of OC, for example, "I enjoy social activities. I have a teamwork at the bank" $(\beta=0.134, \mathrm{R}=0.354$, and $\mathrm{R} 2=0.125)$, "I feel missing the team work at the bank when work with them is terminated" $(\beta=0.215, \mathrm{R}=0.269$, and $\mathrm{R} 2=0.070)$, "my best friends are from within the teamwork at the bank" $(\beta=0.186, \mathrm{R}=0.224$, and $\mathrm{R} 2=0.050)$, and "I enjoy working with the team members at the bank" $(\beta=0.318, R=0.480$, and $R 2=0.230)$ and "the team of the bank is a significant social group to which $I$ belong" ( $\beta=0.365, \mathrm{R}=0.451$, and $\mathrm{R} 2=0.203$ ). Thus, the null hypothesis is rejected because OC (IATG-S) and OP have a statistical relationship at the significance level of 0.01 .

\subsection{The Relationship between OC (Group Integration-Task) and OP}

According to Table 7, the regression-coefficient between OC (IATG-T) and OP is R=0.695 and R2=0.483. This means that the OP can be explained by the dimensions of OC, for example, "the team of the bank seeks to achieve the desired goals" $(\beta=0.328, R=0.571$, and $R 2=0.326)$, "the team of the bank bears responsibility for any loss or bad performance" $(\beta=0.278, \mathrm{R}=0.575$, and $\mathrm{R} 2=0.330)$, "members of the team of the bank have 
different ambitions" $(\beta=0.132, \mathrm{R}=0.561$, and $\mathrm{R} 2=0.314)$, and "the team of the bank are looking forward to solving the problems they face at work" $(\beta=0.066, \mathrm{R}=0.508$, and $\mathrm{R} 2=0.258)$ and "team members of the bank communicate freely among themselves" $(\beta=0.141, \mathrm{R}=0.275$, and $\mathrm{R} 2=0.075)$. Therefore, there is enough empirical evidence to reject the null hypothesis.

Table 7. MRA results for OC (GI-T) and OP

\begin{tabular}{|c|c|c|c|}
\hline The Variables of OC (Group Integration-Task) & Beta & $\mathrm{R}$ & $\mathrm{R}^{2}$ \\
\hline 1. The team of the bank seeks to achieve the desired goals . & $0.328^{* *}$ & 0.571 & 0.326 \\
\hline 2. The team of the bank bears responsibility for any loss or bad performance. & $0.278^{* *}$ & 0.575 & 0.330 \\
\hline 3. Members of the team of the bank have different ambitions. & $0.132^{*}$ & 0.561 & 0.314 \\
\hline 4. The team of the bank are looking forward to solving the problems they face at work. & 0.066 & 0.508 & 0.258 \\
\hline 5. Team members of the bank communicate freely among themselves. & $0.141^{* *}$ & 0.275 & 0.075 \\
\hline - $\quad$ Multiple Correlation Coefficients (MCC) & & 0.702 & \\
\hline - $\quad$ Determination of Coefficient (DF) & & 0.493 & \\
\hline - $\quad$ The Value of Calculated F & & 60.165 & \\
\hline - Degree of Freedom & & 5,309 & \\
\hline - The Value of Indexed F & & 3.01 & \\
\hline - Level of Significance & & 0.01 & \\
\hline
\end{tabular}

Note. $* \mathrm{P}<.05 ; * * \mathrm{P}<.01$.

\subsection{The Relationship between OC (Group Integration-Social) and OP}

Table 8. MRA results for OC (GI-S) and OP

\begin{tabular}{llcc}
\hline The Variables of OC (Group Integration-Social) & Beta & $\mathrm{R}$ & $\mathrm{R}^{2}$ \\
\hline 1. $\quad$ Team members seek to work as a team. & $0.353^{* *}$ & 0.590 & 0.348 \\
2. Scarcely does the teamwork of the bank work individually. & $0.271^{* *}$ & 0.555 & 0.308 \\
3. The bank's teamwork spend some time together at the time of the annual holiday. & $0.180^{* *}$ & 0.587 & 0.344 \\
4. Team members communicate with each other effectively outside of work. & $0.049^{* *}$ & 0.494 & 0.244 \\
- Multiple Correlation Coefficients (MCC) & 0.699 \\
- Determination of Coefficient (DF) & 0.489 \\
- The Value of Calculated F & 74.128 \\
- Degree of Freedom & 4,310 \\
- The Value of Indexed F & 3.31 \\
- Level of Significant & & 0.01 \\
\hline
\end{tabular}

Note. $* \mathrm{P}<.05 ; * * \mathrm{P}<.01$.

According to Table 8, the regression-coefficient between OC (IATG-T) and OP is R= 0.695 and R2 $=0.483$. This means that the OP can be explained by the dimensions of OC, for example, "team members seek to work as a team" ( $\beta=0.353, R=0.590$, and $R 2=0.348)$, "scarcely does the teamwork of the bank work individually" ( $\beta=$ $0.271, \mathrm{R}=0.555$, and $\mathrm{R} 2=0.308)$, "the bank's teamwork spend some time together at the time of the annual holiday" $(\beta=0.180, \mathrm{R}=0.587$, and $\mathrm{R} 2=0.344)$, and "team members communicate with each other effectively outside of work" ( $\beta=0.049, \mathrm{R}=0.494$, and $\mathrm{R} 2=0.244)$. Thus, the null hypothesis is rejected because OC (GT-S) and OP have a statistical relationship at the significance level of 0.01 .

\section{Discussion of Research Findings}

Our findings support the view that the dimensions of OC (IATG-T, IATG-S, GI-T, and GI-S) were positively 
related with OP. The results are consistent with research conducted by Keller (1986); Zaccaro (1991); Mullen \& Copper (1994); Podsakoff et al. (1997); Craig \& Kelly (1999); Elenkov (2002); Patterson et al. (2005); Rachhpal et al. (2012).

The results support the view that OC significantly and positively influences OP. This is consistent with the finding that the employees who believed their banks had OC were high OP. The results are consistent with research conducted by Evans \& Dion (1991); Gully et al. (1995); Langfred (1998); Harun \& Mahmood (2012).

The findings reveal that the $\mathrm{OC}$ was positively related with OP. Overall findings from this study suggested that OC does affect OP. Hence management should ensure that OC be applied in the organization through the encouragement of cooperative teamwork. The results are consistent with research conducted by Zaccaro \& Lowe (1988); Keller (1992); Mullen \& Copper (1994); Harun \& Mahmood (2012).

Our findings support the view that more OC are more effective in achieving OP. High OC will be more likely to achieved high profit. The results are consistent with research conducted by Shaw (1981); Dorfman \& Stephan (1984); Hunger \& Wheelan (1984); Dyaram \& Kamalanabhan (2005).

The results support the view that the high OC would lead to more team success, more collective efficacy, better group communication, and more satisfaction of the group members. The results are consistent with research conducted by Bettenhausen (1991); Harun \& Mahmood (2012).

The results demonstrated that OC do have a significant relationship with OP in the context of Egyptian commercial banks. These findings support the conclusion of Mullen \& Cooper (1994) and Loughead \& Carron (2004) that OC is more likely to influence OP.

Carless \& De Paola (2000) suggested that members who work in the OC believed that OP was the principal focus at any situation, but Carron et al. (2002) found that they have a moderate relationship. Hence, strong relationship will reflect a higher OP.

Hoegl \& Proserpio (2004) indicated that if people are close to one another, better OP is facilitated. Therefore, organizations should obtain stronger learning capability and work environments characterized by OC to improve OP. The strong evidence of significant correlations between OC and OP may provide cooperative members, leaders and managers with a validated knowledge that enables them to strengthen their $\mathrm{OC}$ at various levels (Tan \& Selvarani, 2008).

\section{Conclusion}

Group Integration Social (GI-S) has significant relationship with OP whereas Individual Attraction to the GroupTask (ATG-T), Group Integration Task (GI-T) and Individual Attraction to the Group-Social (ATG-S) have significant relationship with OP.

Individual Attraction to the Group-Task (ATG-T) has significant relationship with OP whereas Individual Attraction to the Group-Social (ATG-S), Group Integration Task (GI-T) and Group Integration Social (GI-S) have significant relationship with OP.

Individual Attraction to the Group-Social (ATG-S) Individual Attraction to the Group-Task (ATG-T)) has significant relationship with OP, Group Integration task (GI-T) and Group Integration Social (GI-S) have significant relationship with OP.

OC correlates with OP and there is a need to realize and create awareness, especially for top management who rely on groups in expecting high results about its effect.

The results offer new perspectives for cooperative movement where members' strong relationship can further contribute to the growth of its OP. The degree of OC among members determine the success of OP in moving toward its future direction (Sapran, 2010; Tan \& Selvarani, 2008).

\section{References}

Baum, J., \& Singh, J. (1994). Organizational niches and the dynamics of organizational mortality. American Journal of Sociology, 100, 346-80. http://dx.doi.org/10.1086/230540

Bettenhausen, K. L. (1991). Five years of group research: What we have learned and what needs to be addressed. Journal of Management, 17, 345-381. http://dx.doi.org/10.1177/014920639101700205

Boone, K., Beitel, P., \& Kuhlman, J. (1997). The effects of the win/loss record on cohesion. Journal of Sport Behavior, 20, 125-134.

Carless, S., \& DePaola, C. (2000). The measurement of cohesion in work teams. Small Group Research, 31(1), 
71-88. http://dx.doi.org/10.1177/104649640003100104

Carroll, G., \& Delacroix, J. (1982). Organizational mortality in the newspaper industries of Argentina and Ireland: An ecological approach. Administrative Science Quarterly, 27, 169-198. http://dx.doi.org/10.2307/2392299

Carron, A., Brawley, L., \& Widmeyer, W. (1998). The measurement of cohesiveness in sport groups. In J. Duda (Ed.), Advances in sport and exercises psychology measurement. Morgantown: WV: Fitness Information Technology.

Carron, A., Widmeyer, N., \& Brawley, L. (1985). The development of an instrument to assess cohesion in sport teams: The group environment questionnaire. Journal of Sport Psychology, 7(3), 244-266

Carron, A. (1982). Cohesiveness in sport groups: Interpretations and considerations. Journal of Sport Psychology, 4(2), 123-138.

Carron, A., \& Brawley, L. R. (1985). The development to assess cohesion in sports teams. Journal of Sport Psychology, 7, 244-266.

Carron, A., Brawley, L., \& Widmeyer, W. (2002). The group environment questionnaire test manual. Morgantown, WV: Fitness Information Technology.

Carron, A., Bray, S. R., \& Eys, M. A. (2002). Team cohesion and team success in sport. Journal of Sports Sciences, 20, 119-126. http://dx.doi.org/10.1080/026404102317200828

Carron, A., Colman, M., Wheeler, J., \& Stevens, D. (2002). Cohesion and performance in sport: A metaanalysis. Journal of Sport \& Exercise Psychology, 24, 168-188.

Chelladurai, P., \& Carron, A. (1982). Leadership. Ottawa Ontario: Canadian Association of Health, Physical Education and Recreation.

Chidambaram, L., \& Jones, B. (1996). Impact of communication media and computer support on group performance: A comparison of face-to-face and dispersed meeting. MIS Quarterly, 17(4), 465-489. http://dx.doi.org/10.2307/249588

Clark, R., Hartline, M., \& Jones, K. (2009). The effects of leadership style on hotel employees' commitment to $\begin{array}{llll}\text { service quality. Cornell Hospitality } & \text { Quarterly, 50(2), }\end{array}$ http://dx.doi.org/10.1177/1938965508315371

Collis, D., \& Montgomrey, C. (1995). Competing on resources: Strategy in the 1995s.

Corey, E. (1992). The development of markets for new materials boston: Division of research. Graduate School of Business Administration.

Cota, A., Evans, C., Dion, K. L., Kilik, L., \& Longman, R. S. (1995). The Structure of group cohesion. Pers Soc Psychol B, 21(6), 572-580. http://dx.doi.org/10.1177/0146167295216003

Craig, T., \& Kelly, J. (1999). Group cohesiveness and creative performance. Group Dynamics: Theory, Research and Practice, 3(4), 243-256. http://dx.doi.org/10.1037/1089-2699.3.4.243

Darroch, J. (2003). Developing a measure of knowledge management behaviors and practices. Journal of Knowledge Management, 7(5), 41-54. http://dx.doi.org/10.1108/13673270310505377

Dion, K. (2000). Group cohesion: From "field of forces" to multidimensional construct. Group Dynamics. Theory, Research, and Practice, 4, 7-26. http://dx.doi.org/10.1037/1089-2699.4.1.7

Dorfman, P., \& Stephan, W. (1984). The effects of group performance on cognitions, satisfaction, and behavior: A process model. Journal of Management,10(2), 173-192. http://dx.doi.org/10.1177/014920638401000203

Dyaram, L., \& Kamalanabhan, T. (2005). Unearthed: The other side of group cohesiveness. Journal of Social Sciences, 10(3), 185-190.

Elenkov, D., (2002). Effects of leadership on organizational performance in Russian companies. Journal of Business Research, 55, 467-480. http://dx.doi.org/10.1016/S0148-2963(00)00174-0

Evans, C., \& Dion, K. (1991). Group cohesion and performance: A meta analysis. Small Group Research, 22(7), 175-186. http://dx.doi.org/10.1177/1046496491222002

Gardner, D., Shields, D., Bredemeier, B., \& Bostrom, A. (1996). The relationship between perceived coaching behaviors and team cohesion among baseball and softball players. Sport Psychologist, 10, 367-381.

Gully, S., Devine, D., \& Whitney, D. (1995). A meta analysis of cohesion and performance: Effects of level of 
analysis and task interdependence. Small Group Research, 26(4), 497-520. http://dx.doi.org/10.1177/1046496495264003

Harun, M., \& Mahmood, R. (2012). The relationship between group cohesiveness and performance: An empirical study of cooperatives movement in Malaysia. International Journal of Cooperative Studies, 1(1), 15-20.

Hoegl, M., \& Proserpio, L. (2004). Team member proximity and teamwork in innovative projects. Research Policy, 33(8), 1153-1165. http://dx.doi.org/10.1016/j.respol.2004.06.005

Hunger, J., \& Wheelen, T. (1984). The relationship between group dynamics and team performance in business simulation. Academy of Management, 10, 43-45.

Keller, K. (1986). Conceptualizing, measuring and managing customer-based brand equity. Journal of Marketing, 57, 1-22. http://dx.doi.org/10.2307/1252054

Keller, R. (1986). Predictors of the performance of project groups in R\&D organizations. Academy of Management Journal, 29, 715-726. http://dx.doi.org/10.2307/255941

Keller, R. (1992). Transformational leadership and the performance of research and development project groups. Journal of Management, 18(3), 489-501. http://dx.doi.org/10.1177/014920639201800304

Langfred, C. (1998). Is group cohesiveness a double-edged sword? An investigation of the effects of cohesiveness on performance. Small Group Research, 29(1), 124-143. http://dx.doi.org/10.1177/1046496498291005

Li, F., \& Harmer, P. (1996). Confirmatory factor analysis of the group environment questionnaire with an intercollegiate sample. Journal of Sport and Exercise Psychology, 18, 49-63.

Loughead, T., \& Carron, A. (2004). The mediating role of cohesion in the leader behavior- satisfaction relationship. Psychology of Sport and Exercises, 5, 355-371. http://dx.doi.org/10.1016/S14690292(03)00033-5

Miller, K., \& Bromiley, P. (1990). Strategic risk and corporate performance: An analysis of alternative risk measure. Academy of Management Journal, 33(4), 756-779. http://dx.doi.org/10.2307/256289

Mitchell, T. (1982). People in organizations: An introduction to organizational behavior (2nd ed.). New York, McGraw-Hill.

Mullen, B., \& Copper, C. (1994). The relation between group cohesiveness and performance: An integration. Psychological Bulletin, 115(2), 210-227. http://dx.doi.org/10.1037/0033-2909.115.2.210

O'Reilly, C., Chatman, J., \& Caldwell, D. (1991). People and organizational culture: Aprofile comparison approach to assessing person-organization fit. Academy of Management Journal, 34, 487-516. http://dx.doi.org/10.2307/256404

Patterson, M., Carron, A., \& Loughead, T. (2005). The influence of team norms on the cohesion-self-reported performance relationship: A multi-level analysis. Psychology of Sport and Exercise, 6, 479-493. http://dx.doi.org/10.1016/j.psychsport.2004.04.004

Podsakoff, P., MacKenzie, S., \& Ahearne, M. (1997). Moderating effects of goal acceptance on the relationship between group cohesiveness and productivity. Journal of Applied Psychology, 82, 974-983. http://dx.doi.org/10.1037/0021-9010.82.6.374

Prapavessis, H., \& Carron, A. (1997). Cohesion and work output. Small Group Research, 28(2), $294-301$. http://dx.doi.org/10.1177/1046496497282006

Rachhpal, S., Kanchan, \& Tarandeep. (2012). Relationship between team cohesion and performance in ball games. VSRD Technical \& Non-Technical Journal, 3(5), 191-196.

Robbins, S. (1993). Organizational behavior (4th ed.). New Jersey: Prentice-Hall, Inc.

Sapran, A. (2010). Exploiting cooperative movement strengths. Pelancar, 37, 10-11.

Shaw, M. (1981). Group dynamics: The psychology of small group behavior (3rd ed.). New York: McGraw-Hill.

Shields, D., Gardner, D., Bredemeier, B., \& Bostro, A. (1997). The relationship between leadership behaviors and group cohesion in team sports. Journal of Psychology, 131, 196-210. http://dx.doi.org/10.1080/00223989709601964

Stogdill, R. (1972). Group productivity, drive, and cohesiveness. Organizational Behavior \& Human 
Performance, 8(1), 26-43. http://dx.doi.org/10.1016/0030-5073(72)90035-9

Sullivan, P., Short, S., \& Cramer, K. (2002). Confirmatory factor analysis of the group environment questionnaire with coasting sports. Perceptual and Motor Skills, 94, 341-347. http://dx.doi.org/10.2466/pms.2002.94.1.341

Tan, C., \& Selvarani, P. (2008). Coping with cooperatives. New Sunday Times.

Wit, B., \& Meyer, R. (1998). Strategy, process, content, context: An international perspective. Thompson Business Press.

Zaccaro, S. (1991). Nonequivalent associations between forms of cohesiveness and group-related outcomes: Evidence for multidimensionality. Journal of Social Psychology, 131, 387-399. http://dx.doi.org/10.1080/00224545.1991.9713865

Zaccaro, S., \& Lowe, C. (1988). Cohesiveness and performance on an additive task: Evidence for multidimensionality. Journal of Social Psychology, $128, \quad$ 547-558. http://dx.doi.org/10.1080/00224545.1988.9713774

\section{Copyrights}

Copyright for this article is retained by the author(s), with first publication rights granted to the journal.

This is an open-access article distributed under the terms and conditions of the Creative Commons Attribution license (http://creativecommons.org/licenses/by/3.0/). 